\title{
Neurocognitive deficits in a patient with small cell lung cancer: a
}

\section{case report}

\author{
Kanan H Hudhud, Ashiq Masood*, Yun Oh and AZ Hegazi
}

Address: Cancer Care Center of Frederick, 46 B, Thomas Johnson Dr. Frederick, MD 21702, USA

Email: Kanan H Hudhud - khudhud@fredonc.com; Ashiq Masood* - ashiqmsd@yahoo.com; Yun Oh - yoh@fredonc.com; AZ Hegazi - zhegazi@fredonc.com

* Corresponding author

Published: 27 October 2008

Cases Journal 2008, I:278 doi:10.1 186/1757-1626-1-278

This article is available from: http://www.casesjournal.com/content/l/I/278

(c) 2008 Hudhud et al; licensee BioMed Central Ltd.

This is an Open Access article distributed under the terms of the Creative Commons Attribution License (http://creativecommons.org/licenses/by/2.0), which permits unrestricted use, distribution, and reproduction in any medium, provided the original work is properly cited.
Received: 10 September 2008

Accepted: 27 October 2008

\begin{abstract}
Introduction: The neurocognitive deficits associated with small cell lung cancer include metastasis to brain and paraneoplastic syndrome. The patients are also predisposed to herpes encephalitis due to immunosuppression and chemotherapy.
\end{abstract}

Case presentation: We report a case of 72 year old female diagnosed with small cell lung cancer started with memory deficits, ataxia, vertigo, and hearing loss. The paraneoplastic work-up returned as anti-Hu antibody positive. The MRI brain showed area of edema and inflammation right medial temporal lobe as well as enhancement in the underlying meningi. Although PCR/HSV of CSF was negative, the patient was empirically treated with IV acyclovir and showed significant improvement and was discharged in good condition.

Conclusion: The case highlights the importance of keeping broad minded approach in treating patients with serious malignant diseases. The case also call attention to the use of empiric therapy in possible life threatening diseases such as Herpes encephalitis

\section{Introduction}

We report a case of 72 year old female diagnosed with small cell lung cancer started with neurocognitive deficits over the few weeks. The patient was empirically treated for suspected herpes encephalitis on the basis of clinical and MRI findings with acyclovir and showed significant improvement.

\section{Case presentation}

In May 2008, 72 year old female was diagnosed of small cell lung cancer incidentally after she was hospitalized for anxiety and dizziness. She was hyponatremic and series of tests which included a CT scan of the chest which showed right hilar lymphadenopathy and mediastinal lymphadenopathy (Figure 1). She then had a mediastinoscopy which was consistent with small cell lung cancer. PET/CT scan findings were consistent with CT scan. She was staged as limited stage small cell carcinoma of lung. She was started treatment with etopside and carboplatin. In July2008, after receiving two cycles of chemotherapy, she presented with new onset memory difficulties.

Further work-up included a MRI of brain with and without gadolinium as well as PET scan showed no evidence of metastatic disease to the brain. These symptoms were thought due to underlying anxiety or depression.

Few days later she started with ataxia, vertigo and hearing loss. She was prescribed meclizine which provided no relief. She then went to emergency department. At that 


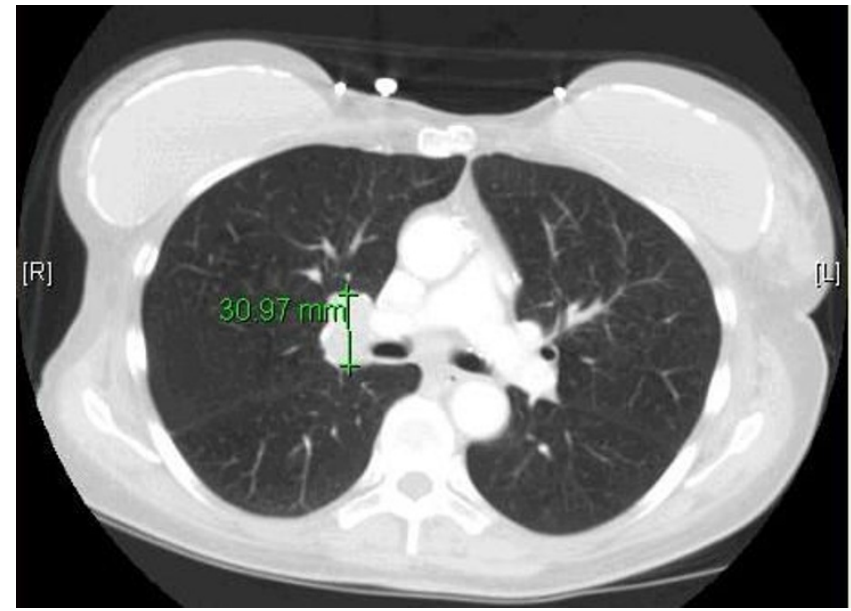

Figure I

CT scan showing right hilar lymphadenopathy.

time she was found to orthostatic. She was rehydrated and discharged.

Audiogram was done which revealed bilateral sensorineural hearing loss greater on the left side. The paraneoplastic workup was sent to rule out paraneoplastic syndrome. The anti-Hu antibody came positive. The diagnosis of anti-Hu syndrome was entertained. She was started on radiation therapy in addition to her chemotherapy for consolidation. She received $3960 \mathrm{cGy}$ of radiation to the mediastinum in August 2008.

Three weeks later, she began developing loss of smell sensation to the point that she was completely anosmic. Her unsteadiness reached to the point that she needed assistance for walking short distance. MRI of brain showed new area of edema and inflammation in the right medial temporal lobe as well as enhancement in the underlying meningi (Figure 2). She was admitted for to the hospital for empiric IV acyclovir therapy for possible herpes encephalitis. The Lumber puncture was done which showed increased proteins (Total proteins $5.7 \mathrm{~g} / \mathrm{l}$, Beta globulin of $0.73 \mathrm{~g} / \mathrm{l}$ ) and lymphocytes. The CSF HSV/PCR was negative. Patient was discharged in the 6 th day from the hospital and received total 10 days of IV acyclovir as she improved on the treatment. Patient is now planned for further chemoradiation therapy.

The neurocognitive deficits in our patient were probably because of either anti-Hu syndrome or Herpes encephalitis.

The anti HU syndrome is a neurologic paraneoplastic syndrome. A specific anti body called anti HU is present in serum and CSF of these patients [1]. Patients with anti-Hu

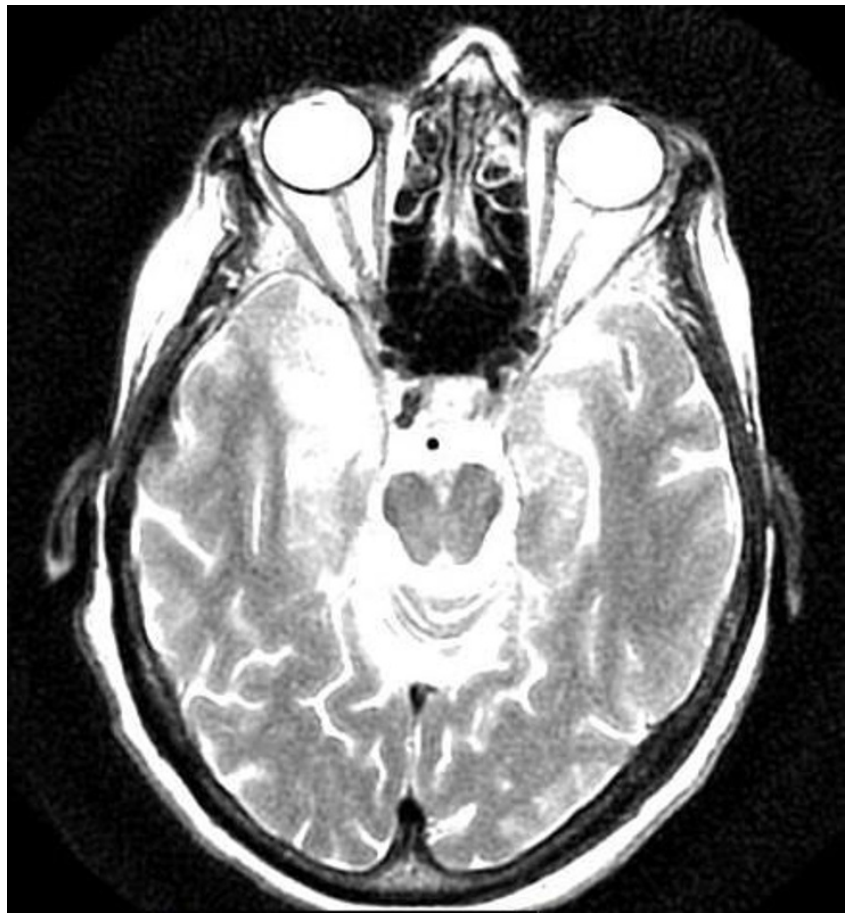

Figure 2

MRI showing abnormal signal intensity involving the medial aspect of the right temporal lobe.

antibodies usually have SCLC (94\%), multifocal neurological symptoms and a poor prognosis [2]. Anti-Hu encephalomyelitis is one of the most frequent paraneoplastic syndromes, classically presenting with diffuse neurological involvement [3]. Anti-Hu antibodies are present in about $50 \%$ of patients with limbic encephalitis and lung cancer and is characterized by marked reduction in short term memory and sub acute confusion. Many patients may also develop rapid pancerebellar dysfunction due to extensive purkinjee neuronal loss termed as sub acute cerebellar ataxia. The HU-Abs is reported to be present in about $23 \%$ of these patients. The Anti-Hu antibodies, in addition to SCLC are associated with prostate cancer and neuroblastoma [4].

Anti-HU antibodies are also associated with Encephalomyelitis, sensory neuropathy, and autonomic neuropathy. The limbic encephalitis and sub acute cerebellar degeneration are associated relatively often with cancer and are called "classical" PNS [5]. The treatment of PNS is control of the tumor. Antitumor treatment has established to stop paraneoplastic neurological deterioration. However, in debilitated patients treatment of underlying tumor is withheld because of the little chance of clinically relevant neurological improvement [5]. 
Herpes simplex encephalitis patients may have a prodrome of malaise, fever, headache, and nausea that is followed by acute or sub acute onset of an encephalopathy whose symptoms include lethargy, Confusion, and delirium. Patients may also have seizures, aphasia, and other focal neurological deficits. The herpes encephalitis is fatal in 7 to 14 days if not treated and mortality as high as $70 \%$ in untreated cases. Neurology consultation should be sought as HSV encephalitis is neurologic emergency and treatment should be started with acyclovir in suspicious cases or when diagnosis is established. [6] In our case, the patient developed anosmia and that can be present in $65 \%$ of patients of HSV encephalitis [7]. However, PCR of spinal fluid for HSV was negative. PCR itself has a reported sensitivity of $98 \%$ and a specificity of $94 \%$ for the detection of HSV in the CSF [8].

False negative results may occur: [9]

1. Occasionally in bloody specimens through inhibition of PCR

2. When CSF has been obtained after starting Acyclovir.

3. When lumbar puncture has been performed early in disease.

4. When lumbar puncture was delayed approximately 10 days or more into the disease process

Since a negative HSV PCR result does not entirely rule out the possibility of HSE, an intrathecal antibody response specific to HSV should also be sought [9].

Although we did not prove the agent microbiologically but the MRI changes and Clinical improvement, elevated proteins and lymphocytes in CSF points towards HSV encephalitis. Our next step is try to get diagnosis retrospectively by measuring serial serum and CSF titers although it has no role in acute diagnosis and treatment [10].

\section{Conclusion}

The case emphasizes the diagnostic challenge the patients with small cell lung cancer may present and clinicians may end up treating patients empirically for suspected infectious pathology. The case also demonstrates the need to use empiric therapy in suspected life threatening diseases such as Herpes encephalitis.

\section{Abbreviations}

SCLC: Small cell lung cancer; HSV: Herpes simplex encephalitis.

\section{Consent}

Written informed consent was obtained from the patient for publication of this case report and accompanying images. A copy of the written consent is available for review by the Editor-in-Chief of this journal.

\section{Competing interests}

The authors declare that they have no competing interests.

\section{Acknowledgements}

We are thankful to Noora Amatullah Masood for helping us preparing this manuscript and taking time from her busy schedule along with five months old Zayan Masood.

\section{References}

I. Chartrand-Lefebvre C, Howarth N, Grenier P, Keime F, Orcel B, Beigelman C: Association of small cell lung cancer and the anti-Hu paraneoplastic syndrome: radiographic and CT findings. American Journal of Roentgenology 1998, 170:1513-1517.

2. Pearce JMS: Paraneoplastic Limbic Encephalitis. Eur Neurol 2005, 53: I06-108.

3. Compta Y, Valldeoriola F, Urra X, Gomez-Anson B, Rami L, Tolosa $\mathrm{E}$, Graus $\mathrm{F}$ : Isolated frontal disequilibrium as presenting form of anti-Hu paraneoplastic encephalomyelitis. Movement disorders 2007, 22(5):736-738.

4. Honnorat J, Antoine JC: Paraneoplastic neurological syndromes. Orphanet J Rare Dis 2007, 42:22.

5. de Beukelaar JW, Smitt PAS: Managing paraneoplastic neurological disorders. The Oncologist 2006, I I:292-305.

6. Anderson WE: HerpesSimpleEncephalitis. [http://www.emedi cine.com/neuro/TOPICI59.HTM].

7. Mcgrath, Anderson NE, Croxson MC, Powell KF: Herpes simplex encephalitis treated with acyclovir: diagnosis and longterm outcome. Neurol Neurosurg Psychiatry 1997, 63:321-326.

8. Khan OA, Ramsay A: Herpes encephalitis presenting as mild aphasia: Case report. BMC Fam Pract 2006.

9. Chataway J, Davies NWS, Farmer S, Howard RS, Thompson EJ, Ward $\mathrm{KN}$ : Herpes simplex encephalitis: an audit of the use of laboratory diagnostic tests. QJM 2004, 97(6):325-330.

10. Pritz T: HerpesSimpleEncephalitis. [http://www.emedicine.com/ emerg/TOPIC247.HTM].

Publish with Bio Med Central and every scientist can read your work free of charge

"BioMed Central will be the most significant development for disseminating the results of biomedical research in our lifetime. "

Sir Paul Nurse, Cancer Research UK

Your research papers will be:

- available free of charge to the entire biomedical community

- peer reviewed and published immediately upon acceptance

- cited in PubMed and archived on PubMed Central

- yours - you keep the copyright

Submit your manuscript here:

http://www.biomedcentral.com/info/publishing_adv.asp
BioMedcentral 